\title{
Incorporating nutrients into meat demand analysis using household budgets data
}

\author{
Ana María Angulo \\ Corresponding author \\ Departamento de Análisis Económico \\ Facultad de Ciencias Económicas y Empresariales, \\ Gran Vía, 2, 50005 Zaragoza (Spain) \\ Phone: 976 761831- Fax: 976761996 \\ E-mail: aangulo@posta.unizar.es \\ José María Gil \\ CREDA-UPC-IRTA \\ Edifici ESAB- Parc Mediterrani de la Tecnologia \\ Av. del Canal Olimpic, s/n \\ 08860-Castelldefels (Barcelona-Spain) \\ Phone: 93 5521210- Fax: 935521121 \\ E-mail: chema.gil@upc.edu
}

\begin{abstract}
The objective of this paper is to analyze the Spanish demand for meat taking into account the consumer's concern about the relationship between food diet and health. This concern is forcing food demand analysts to assume that consumer utility is a function of nutrients instead of simply the food products themselves. Nevertheless, these utility function arguments are not produced in the marketplace but rather at home. As a consequence, in this paper household production theory is followed in order to analyze Spanish demand for meat using the Quarterly National Expenditure Survey for 1999. Demands for several meat products (the input in the model) are derived from the translog cost function. Censored regression models are used in the estimation process, since many zero responses are reported. Five broad categories, eight nutrients and the most relevant socio-economic variables are considered. Finally, a set of elasticities is calculated with respect to all the variables included in the analysis.
\end{abstract}

JEL Classification: D13, C24, I12

Key words: Spanish meat demand; Nutrient intakes; Health awareness; Household production theory; Zero expenditures.

Submitted 7.16.03 Revised received 2.01.05 Accepted 8.04.05 


\section{Introduction}

In recent years there has been a general concern about the relationship between health and food diet. In most developed economies the incidence of cancer, cardiovascular disease and other mortal diseases is growing at an alarming rate. Willet (1994) has pointed out that an unbalanced food diet could explain this trend.

In the last twenty years a number of papers have analyzed this relationship. Capps and Schmitz (1991), Burton and Young (1996), Kinnucan et al. (1997), Kim and Chern (1999), and Ben Kaabia et al. (2001), among others, incorporate so-called "health information indexes" into food demand systems in order to take into account the effect of the consumer's knowledge about the relation between nutrients and health. As regards cross-sectional data analyzes, most of the literature incorporating nutritional information measures the impact of income, prices and socio-demographic variables on nutrient intakes. Two different measurement techniques are typically used. 'Direct' measurements are obtained through a regression of nutrient intake on relevant variables (Adrian and Daniel, 1976; Nayga, 1994; Ramezani, 1995; Subramanian and Deaton, 1996; Chesher, 1998; among others). Alternatively, 'indirect' measurements are made in two steps. First, the relevant variable effects on the demand for food products are calculated by estimating a demand system. Then, nutrient intake effects are obtained by applying nutrient conversion factors to these food effects (Xiao and Taylor, 1995; Ramezani et al., 1995; and Huang, 1999).

Nevertheless, most studies that use cross-sectional data analyze the demand for nutrients more than the demand for food. The applicability of such results is limited, since nutrients are not directly available in the market. It would be more useful to incorporate the new nutrient intake awareness into a demand model that enables us to make conclusions about food demand (in terms of changes in quantities consumed of different products) rather than nutrient demand.

The aim of this paper is to use such an approach to analyze the Spanish demand for meat. Apart from other nutritional characteristics, meat products, together with eggs, cow's milk and fish, are often referred as high-quality protein providers for human health. Although from the standpoint of nutrition, the human body does not require proteins per se, it requires essential amino acids that are present in dietary proteins. They are called essential as they 
cannot be synthesized by mammals, at least in the amounts needed, and are therefore essential constituents of a balanced diet for humans. ${ }^{1}$

From the methodological point of view it is assumed that the consumer utility function is a function of nutrients and not of the goods themselves. It is not unrealistic to assume that consumers are starting to think more in terms of food nutrients than in terms of food products, while also taking into account prices and disposable income. Also, it is assumed that these utility function arguments are best obtained through a household production technology, using the consumed food products as the main inputs. Once a functional form for the obtained cost function is adjusted, the analysis of food demand can be carried out as an analysis of input demand. Finally, the model is improved incorporating certain socio-economic variables. The model is estimated using the Quarterly National Expenditure Survey for 1999. Since a large number of zero purchases are reported, several models taking this problem into account are estimated and tested.

The paper is organized as follows. The next section presents some descriptive data on meat demand in Spain. Afterwards, the theoretical model is explained. Next, the data are described and then the main results are presented. The paper ends with some concluding remarks.

\section{The demand for meat in Spain}

Spanish food demand structure has stabilized in the last few years. According to data from the Quarterly Household National Expenditure Survey for 1999, the average budget shares of different types of meat, fish and eggs in relation to total food expenditure were: beef, $9.12 \%$; pork, $6.42 \%$; poultry, $6.71 \%$; fish, $11.54 \%$; and, finally, eggs, $2.66 \%{ }^{2}$ However, important family differences appear in relation to certain household characteristics, as shown in Table 1. Fish has the largest share for all categories of household listed, except when the education level is 'secondary school', when the age of the household head is under 30 and when the percentage of members between 14 and 29 years old exceeds 75\%; in each of these cases the share of beef is the largest. Pork has the second largest share only in rural areas and the egg expenditure share is the lowest for all products. As the level of education of the head of the household increases, fish expenditure shares increase, while pork, poultry and 
egg shares decrease. Similarly, as the size of the town of residence increases, beef and fish expenditure shares increase and the pork share decreases. As regards household size, it is observed that while in the cases of pork, poultry and eggs the highest expenditure share corresponds to relatively large households ( 5 or more members), in the cases of beef and fish it corresponds to smaller households (4 and 2 members for beef and fish, respectively). Finally, regarding age, it is observed that as the percentage of members under 14 years old increases, more of the food budget is spent on pork and poultry.

\section{(Insert Table 1)}

Table 2 presents information on the contribution of meat products to total nutrient intake. Nutrients have been aggregated into the following eight broad categories: energy, proteins, carbohydrates, lipids, vitamins, fibre, calcium and other minerals. Jointly considered, meats, fish and eggs provide $16 \%$ of the total energy intake, $44 \%$ of the total protein intake, $27 \%$ of the lipid intake as well as an important percentage of other minerals and vitamins.

(Insert Table 2)

\section{Methodology}

The basic assumption of the model is that, at least in more developed countries, nutrient intake is becoming a more important determinant of food demand. In this paper it is assumed that the consumer's preferences are influenced by food characteristics. This approach is in line with the consumer goods characteristics model introduced by Ladd and Suvannunt (1976) and the hedonic model discussed by Nerlove (1995) ${ }^{3}$. In this scheme, consumers have complete quasi-ordering over the set of all possible characteristic collections, which requires that preference ordering is transitive and complete. Furthermore, continuity and strict convexity assumptions are also satisfied. ${ }^{4}$ Nevertheless, in this framework, assumptions of non-satiation and positive desire of all characteristics cannot be satisfied in all cases. ${ }^{5}$ That is, there is nothing to guarantee that consumers' reaction to all characteristics are always positive, in the sense that everyone prefers more rather than less of each characteristic, other things being equal. Due to this fact, in this approach, it is necessary to 
determine how to deal with 'negative' characteristics. Following Lancaster (1971), the appropriate strategy depends on the universality of such 'negative' reactions. That is, if the reaction to a characteristic is universally negative (everyone prefers less of a certain characteristic), the general structure of the analysis is preserved by simply taking the negative of that characteristic. But it may be the case that some individuals can react to the same characteristic positively while others react negatively, or even that a particular individual can react positively at certain levels and negatively at others. In such cases, the efficiency criteria are no longer universal. Whether to adopt the sign change technique when there are divided reactions to a given characteristic is a matter of choice on an ad hoc basis. If the distribution of preferences were such that most consumers viewed the characteristics negatively, it would presumably be convenient to change its sign; otherwise, it would be better to preserve it.

Following household production theory (Becker, 1965; Lancaster, 1971), we assume that the vector $a=\left[a_{1}, \ldots, a_{r}, a_{r+1}, \ldots, a_{p}\right]$ represents the levels of $r$ nutrients and $p-r$ characteristics provided by food products (taste, smell, appearance, etc.). Of course, the components of $a$ are not directly sold in the market but they must be obtained using different types of inputs. Furthermore, let $q=\left[q_{1}, \ldots, q_{n}, l_{1}, \ldots, l_{s}\right]$ represent the total set of inputs needed in the production process which can be decomposed into a vector of $n$ food inputs $\left(q_{f}, f=1, \ldots, n\right)$ and $s$ labour inputs $\left(l_{b}, b=1, \ldots, s\right)$ which can be bought in the market at prices $p=\left[p_{1}, \ldots, p_{n}\right.$, $\left.s_{1}, \ldots, s_{s}\right]$. Correspondingly, $p_{f}$ represents the prices of food inputs and $s_{b}$ the wages of labour inputs. In this study, the vector $a$ represents the new argument of the consumer utility function.

Households purchase market goods in quantities $q$ with the purpose of jointly producing non-market commodities $a$ which yield utility according to $U=U(a)$, where $U($ ) is assumed to be quasi-concave. Let the joint production function be $F(q, a)=0 .{ }^{6}$ It is assumed that $F$ ( ) is 'neoclassical'; that is, given $q$, the production possibility frontier in $a$ is concave, and the isoquants in $q$ given $a$ are convex. In addition, the traditional budget constraint $y=p^{\prime} q$ holds. This optimisation problem can be solved in two stages:

In the first stage, the household tries to minimise the cost $\left(C=p^{\prime} q\right)$ of producing any given bundle $a$. From the Lagrangian: $\ell_{1}=p^{\prime} q+\pi(F(q, a))$, the following cost function is obtained, which represents the minimal short-run cost of obtaining a bundle $a$ at given prices 
$p:$

$$
C=C(p, a)
$$

In the second stage of the procedure, the household tries to maximize the utility function $U=U(a)$ subject to the constraint $y=C(p, a)$. Solving the first order conditions derived from the Lagrangian, $\ell_{2}=U(a)+\lambda(y-C(p, a))$, demand functions for the commodities included in bundle $a$ are obtained:

$$
a_{k}=a_{k}(y, \pi) \quad k=1, \ldots, p,
$$

where $y$ is the total budget and $\pi=\left(\pi, \ldots, \pi_{p}\right)$ is the vector of the shadow prices.

Once the theoretical foundation is established, and taking into account that the main interest of this study is to present the final conclusions in terms of products available in the market, we will only concentrate on the first stage of the procedure. This will enable us to form conclusions about food products, considered as the main necessary inputs that enable food consumers to get those commodities they consider valuable.

To attain this objective, a functional form for (1) has to be chosen. The translog cost function is adopted, since it has been widely used in related literature. Formally, this cost function can be written as:

$$
\begin{aligned}
\ln C= & \alpha_{0}+\sum_{i} \alpha_{i} \ln p_{i}+\sum_{k} \beta_{k} \ln a_{k}+1 / 2 \sum_{i} \sum_{j} \alpha_{i j} \ln p_{i} \ln p_{j} \\
& +1 / 2 \sum_{k} \sum_{h} \beta_{k h} \ln a_{k} \ln a_{h}+1 / 2 \sum_{i} \sum_{k} \theta_{i k} \ln p_{i} \ln a_{k}
\end{aligned},
$$

Differentiating (3) with respect to each of the input prices and applying Shephard's lemma, input budget share equations can be derived as follows:

$$
\partial \ln C / \partial \ln p_{i}=w_{i}=\alpha_{i}+\sum_{j} \alpha_{i j} \ln p_{j}+1 / 2 \sum_{k} \theta_{i k} \ln a_{k}
$$

where $\mathrm{w}_{\mathrm{i}}=\mathrm{q}_{\mathrm{i}} \mathrm{p}_{\mathrm{i}} / \mathrm{C}$ is the $\mathrm{i}^{\text {th }}$ input budget share.

The $\alpha$ and $\theta$ parameters show the effect of changes in $p$ and $a$ on factor shares, respectively. If $\theta_{i k}$ equals zero for all $i$ and $k$, the household production technology is 
homothetic, meaning that the input shares are not affected by the levels of various nutrients or food characteristics.

Finally, differences in the expenditure allocation explained by the relevant socioeconomic household characteristics are gathered through the introduction of all these variables (denoted by $\mathrm{SE}_{\mathrm{g}}, \mathrm{g}=1, \ldots, \mathrm{z}$ ), thought the independent term. Then, in (4) $\alpha_{i}$ is substituted by (Pollak and Wales, 1981):

$$
\alpha_{i}^{*}=\alpha_{i}+\sum_{g=1}^{z} \varphi_{i g} S E_{g}
$$

\section{Data and preliminary analyzes}

Data come from the Spanish Quarterly Household National Expenditure Survey, which provides quarterly information on the expenditure and quantity of various classes of food products consumed by a stratified random sample of 3,200 households. Each quarter, information is collected from each household during one week. Theoretically, one household stays in the survey for eight quarters. However, in practice, only a few households stay in the sample for the maximum period. So, for this study, we only include those households that participated throughout the year in question, 1999. This strategy leads to a final sample of 1657 households. Consumption is aggregated in order to obtain yearly food consumption.

The survey gathers information on a limited number of household characteristics including the level of education and main activity of the head of the household, household income, household size, age and sex of family members and town size, among others. Nevertheless, no information is provided either in relation to labour inputs in meal preparation or with respect to the wage paid to meal preparers. As a consequence, the labour variables and the wages are deleted from vectors $q$ and $p$, respectively. In a similar way, while it is possible to measure nutrient intakes by applying conversion factors to the consumed quantities, it is impossible to measure the rest of the perceived food characteristics such as taste, smell or appearance. To be consistent with previous literature ${ }^{7}$, we assume that differences in tastes and in other non-observable attributes are mainly represented by, and are determined by, the differences in household characteristics gathered in (5). 
Using this household information and the model defined in the previous section, we must now isolate meat demand from other food groups. If weak separability of preferences applies, then multistage budgeting would allow us to focus only on meat products without considering the rest, thereby obtaining conditioned demand elasticities. If not, another solution must be found.

Let us consider this question. As the model stands, the consumer utility function depends on attributes obtained from goods instead of depending on the goods themselves. Using this scheme, we suppose that, in general, a food group will be analyzed separately from other types of goods such as clothes, footwear, etc., due to the fact that the marginal substitution relationship between any pair of nutrients (or any other characteristic) will be, in general terms, independent from any type of attribute, as might characterize clothes, footwear, etc. ${ }^{8}$ Nevertheless, does the same statement apply in comparing different food groups such as cereals, meat, fats, vegetables...? In other words, is the marginal substitution relationship between calories and proteins coming from cereals independent from calories coming from meat, for instance? In our view the answer is generally 'no', because a rational consumer tries to get a nutritionally balanced diet without considering the origin of the nutrients. That is, consumers do not distribute their purchases in order to obtain a concrete percentage of total nutrients from a certain food group. They are interested in total nutrient intake. Hence, we can conclude that the second stage of multistage budgeting does not apply to the case under study.

Taking into account the habits of Spanish food consumers as mentioned in Section 2, we analyze the different types of meat for which data are available -beef, pork and poultry- as well as fish and eggs. One of the following two alternatives must be chosen: 1) specify a food demand system with various classes of food products (different types of cereals, meat, fats, vegetables...); or 2) specify a system that includes the meat categories under study together with one last category that covers the rest of the food groups. Although this last category represents a quite heterogeneous aggregate, its equation could be the one deleted from the system to avoid the singularity of the residual matrix due to the adding-up condition of a demand system. The first strategy, although theoretically accurate, results in a less parsimonious model. In addition, the second alternative allows us to concentrate our attention on the demand for animal products. Hence, the second alternative is preferred, although 
separability tests will be carried out to check whether this decision is supported by the data.

Many concepts of separability have been used, including the distinction as to whether there is weak or strong separability, separability of the utility function (direct), separability of the indirect utility function (indirect), separability of the cost or distance function (quasi), separability of an implicit representation of the direct utility function (direct pseudo), and, finally, separability of an implicit representation of the indirect utility function (indirect pseudo). Pudney (1981) provides a formal definition of each and uses them to impose and test separability in a simple constant elasticity model. Although each definition requires a different set of parametric restrictions, Pudney shows that the various definitions available make little difference to the empirical results. Consequently, following Hayes et al. (1990), only the quasi-separability of our cost function will be tested.

Generally, preferences are quasi-separable if the cost function defined in (1) can also be written as:

$$
C(p, a)=G\left[g_{1}\left(p_{1}, a\right), \ldots, g_{d}\left(p_{d}, a\right)\right]
$$

where goods are portioned into $d$ groups with the price subvector $p_{1}, \ldots, p_{d}, G$ is interpreted as a macro cost function and $g_{d}$ is interpreted as a price index for group $d$.

Following Deaton and Muellbauer (1980a, p. 134), the group budget shares $\left(w_{d C}=C_{d} / C\right)$ may be derived from:

$$
w_{d C}=\frac{\partial \ln G}{\partial \ln g_{d}} .
$$

Intragroup budget shares $\left(w_{i d}=p_{i} q_{i} / C_{d}\right)$ may be derived from:

$$
w_{i d}=\frac{\partial \ln g_{d}\left(p_{d}, a\right)}{\partial \ln p_{i d}}
$$

where each vector $p_{d}$ is composed of the prices of the individual commodities $i$ within the group $d$. 
Then, from Shephard's lemma, the share of subgroup $i$ within the total expenditure $\left(w_{i}=p_{i} q_{i} / C\right)$ may be derived from:

$$
w_{i}=\frac{\partial \ln G}{\partial \ln g_{d}} \frac{\partial \ln g_{d}}{\partial \ln p_{i d}}=w_{d C} w_{i d} .
$$

Differentiating (9) with respect to the price of good $j$ in group $e$, we get:

$$
\alpha_{i d j e}=\frac{\partial w_{i}}{\partial p_{j e}}=\frac{\partial^{2} \ln G}{\partial \ln g_{d} \partial \ln g_{e}} \frac{\partial \ln g_{d}}{\partial \ln p_{i d}} \frac{\partial \ln g_{e}}{\partial \ln p_{j e}} .
$$

Taking each variable on the right-hand side of (10) in turn:
i) $\frac{\partial \ln G}{\partial \ln g_{d}}=w_{d C}$
ii) $\frac{\partial \ln w_{d C}}{\partial \ln g_{e}}=\alpha_{d e}$
iii) $\frac{\partial \ln g_{d}}{\partial \ln p_{i d}}=w_{i d}$
iv) $\frac{\partial \ln g_{e}}{\partial \ln p_{j e}}=w_{j e}$,

where $\alpha_{d e}$ is the estimated cross-price parameter between groups $d$ and $e$, which can be estimated from an aggregate model that has shares $w_{d C}$ and $w_{e C}$ as dependent variables. Hence, the restriction that is implied by the quasi-separability of the cost function may be written in terms of known shares and estimated parameters as:

$$
\alpha_{i d j e}=w_{i d} w_{j e} \alpha_{d e} .
$$

In other words, two groups, $d$ and $e$, may be considered separable if the compensated cross-price effects between the share of good $i$ in group $d$ and the price of good $j$ in group $e(e \neq d)$, satisfy the restriction in (11).

In order to implement this procedure, we must first decide which explanatory variables to include in the system. Taking equations (4) and (5) into account, the following variables are included: 1) the logarithm of the prices of the types of meat under consideration as well as the logarithm of a price for the rest of the food groups $;{ }^{9}$ 2) the logarithm of total nutrient intake (kilocalories, carbohydrates, lipids, vitamins, proteins, fibre, calcium and other minerals); and finally, 3) the following socio-economic characteristics of households to capture differences in non-observable food attributes: total per capita food expenditure (as an 
approximation of per capita income), the size of the town in which the household lives, the level of education of the head of the household, the household size and the percentage of household members within several age intervals. The categories considered for the last three variables are those indicated in Table 1. Of these variables, total per capita food expenditure and/or nutrient intakes may not be exogenous ${ }^{10}$. Furthermore, regarding consumers' reaction to nutrients, it is supposed that although there could be divided reactions to some of them (mainly kilocalories and lipids), reactions are far from being universal. ${ }^{11}$ Therefore, following Lancaster, the sign change technique is not adopted in any case.

Next, separability tests are carried out in order to determine whether our previous assumptions are confirmed by the data. The sequential procedure is straightforward. To test the null hypothesis of quasi-separability between meat (beef, pork and poultry) and fish, the following procedure has been followed. First, an estimate of $\alpha_{d e}$ is obtained by using a twogood model to explain the shares of meat and fish. A second model is then estimated in which individual meat and fish group shares are dependent variables. The predicted shares of the individual meats are multiplied by $\alpha_{d e}$ to obtain a set of parametric restrictions that are then placed on the cross-price terms between each meat price and the fish group price. A likelihood ratio test is then performed to determine if the restrictions are accepted by the data. The calculated likelihood ratio is 26.42 , which is higher than the critical value at the $5 \%$ level of significance, $\chi^{2}(3)=7.81$. Hence, at mean values, the null of separability is rejected and, as a consequence, the different types of meat and fish must be incorporated into a single system. Taking this into account, we next determine whether these meat products and eggs can be jointly considered in the system. Following an analogous procedure, we obtain a likelihood ratio of 51.73, which also is greater than the critical one at the $5 \%$ level, $\chi^{2}(4)=9.48$. Hence, beef, pork, poultry, fish and eggs form part of the same demand system. Finally, the analogous procedure is carried out to check the separability of previous products and the aggregate 'rest of food products'. In this case, the likelihood ratio takes a value of 62.96 , higher than the critical value of $\chi^{2}(5)=11.07$, at the $5 \%$ level. Hence, we conclude that the chosen alternative to meet our objective of analysing the demand for different meat products is not rejected by the data.

\section{Estimation results}


Zero expenditure problem

When cross-sectional data are used for the demand analyzes of specific products, a large number of zero purchases can be reported during short survey periods. For instance, for the Spanish data we are using, households have recorded their consumption during only one week. ${ }^{12}$ For this kind of data, an ordinary least squares estimation that is either based on all, or on only the positive responses, generates biased parameter estimates (Amemiya, 1984). In addition, excluding the null responses also causes efficiency losses and, in most cases, inconsistency. Therefore, a model that takes into account the censored nature of the data must be specified.

In early studies, the Tobit model was widely used, but this is only appropriate if the zero observation is a corner solution (it assumes that all households potentially consume the product). In recent studies, other models that take into account different explanations for zero purchases have been used. Generally, there are three reasons for a zero expenditure: 1) the survey period is too short to allow consumers to report the purchase of a specific product (infrequency of purchase), 2) consumers are not willing to buy the product (abstention) and, 3) consumers do not purchase the product at current prices and income levels (corner solution).

Censored demand models can be classified into two broad categories: 1) doublehurdle models and 2) infrequency models. One advantage of these models is that both decisions, whether to buy and how much to buy, may depend on different sets of explanatory variables. In addition, these decisions can be jointly or independently modelled, deriving, respectively, the simultaneous and the independent versions of the models. Let $u_{i}$ and $v_{i}$ be the error terms corresponding to the decisions to buy and how much to buy, respectively. The joint distribution of both error terms in the simultaneous versions of the two broad model categories is given by:

$$
\left(u_{i}, v_{i}\right) \sim B V N(0, \Gamma) \quad \text { where } \Gamma=\left[\begin{array}{cc}
1 & \rho \sigma \\
\rho \sigma & \sigma^{2}
\end{array}\right],
$$

where BVN denotes bivariate normal and $\rho$ is a correlation coefficient. 
On the other hand if $u_{i}$ and $v_{i}$ are assumed to be independent (that is, $\rho=0$ ) and $u_{i} \sim$ $\mathrm{N}(0,1)$, and $\mathrm{v}_{\mathrm{i}} \sim \mathrm{N}\left(0, \sigma^{2}\right)$, the independent versions of two model categories is obtained.

Behind the Double-Hurdle Model (DH) is the idea that a consumer has to overcome two hurdles before making a purchase: 1) to decide to participate in the market (potential consumer); and 2) to actually buy. A zero expenditure is recorded in those cases where consumers either decide not to participate in the market, or having decided to participate, they eventually do not buy. In the first decision, any value of the explanatory variables (price, income, etc.) is irrelevant, so non-purchase is due to conscientious abstention. In the second one, potential consumers do not buy the product due to the existing levels of the explanatory variables. Therefore, the $\mathrm{DH}$ specification is appropriate when zero expenditures result from true non-purchase responses that are based either on conscientious abstentions or economic factors.

The Infrequent Purchase Model also assumes that a consumer faces two decisions before a positive expenditure is recorded. The first decision is whether to purchase or not (purchase decision), and the second decision, to actually buy. As regards zero expenditures, in this model a zero expenditure results from one of two following situations. On one hand, consumers have not purchased because as a habit the item is purchased infrequently (and not because of conscious abstention as in the DH model). On the other, there are consumers who, having decided to purchase, do not buy, basing their decision on economic factors (corner solution). In these cases the interpretation is similar to that in the DH model. This is called the Tobit-Infrequency of Purchase (TIP) model.

There is a particular case in which, having decided to purchase, consumers always buy a positive amount of product (there are no corner solutions). Then the simultaneous/independent TIP model reduces to the simultaneous/independent Infrequency of Purchase Model (IP) defined by Blundell and Meghir (1987).

Many versions of these models have been used in recent years (Blundell and Meghir, 1987; Gao et al., 1995; Burton et al., 1996; Su and Yen, 1996; Yen and Jones, 1997; and Angulo et al., 2001, among others). 


\section{Model selection}

First, the three models defined above, in both versions, simultaneous and independent, are estimated for the five main categories (beef, pork, poultry, fish and eggs) using Time Series Processor software (TSP International, 2005). ${ }^{13}$ The maximum likelihood procedure and Newton's estimation method for parameter covariance matrices are followed. Since heteroscedasticity is likely to be present in the different models, models with heteroscedastic errors are estimated by allowing the standard deviation, $\sigma_{i}$, to vary across observations. In particular, $\sigma_{\mathrm{i}}$ has been reparametrized as follows:

$$
\sigma_{i}=\exp \left(H_{i} \gamma\right)
$$

where $H_{\mathrm{i}}$ represents the set of variables that generates the heteroscedastic problem. The exponential specification has the desired property that the standard deviation, $\sigma_{i}$, is strictly positive. In Table 3 we present the maximum likelihood estimation results for the different models, together with likelihood ratio values for testing the null hypotheses of homoscedastic errors. ${ }^{14}$ As can be observed, in all cases the null hypothesis is rejected and, consequently, heteroscedasticity is introduced in all models.

\section{(Insert Table 3)}

Second, a statistical test for non-nested models (Vuong, 1989) is implemented in order to determine which model best fits the actual consumer purchasing decisions. Results are shown in Table 4. The model selection process is divided in three steps. First, the independent versus the dependent version of each type of model is tested for all products. In all cases, the independent versions of the models seems to better fit the data. In a second step, the ITIP model is tested against the IIP one, since, as mentioned above, IIP is a special case of ITIP. As can be observed, in all cases the ITIP model is preferred. Finally, the ITIP models are tested against the IDH models. The last two rows of Table 4 summarise the results. While for beef, poultry and fish both models yield similar results, in the case of pork and eggs the ITIP models outperforms the IDH models. 
As the Voung test cannot distinguish between ITIP and IDH models for three out of five products, the test for non-nested models proposed by Clarke (2003) is implemented. Results are shown in Table 5 and indicate that the ITIP model outperforms the IDH model for all products but beef for which, as for the Voung test, ITIP and IDH models are not significantly different.

\section{(Insert Table 5)}

Third, we test whether total per capita food expenditure and/or nutrient intakes can be considered independent from the error term (exogeneity) using the Hausman test (Hausman, 1978). An instrument for total per capita food expenditure frequently used in literature is per capita income, which is not available here. In addition, nutrient intakes are also quite difficult to instrument. We have decided to follow Wald (1940), and define each instrument as a dummy variable, which equals 1 when the value of the respective variable is over its mean, and 0 otherwise. The Hausman tests yield the following values: beef, 23.20; pork, 15.91; poultry, 25.42; fish, 41.78; and eggs, 19.56. As all these values are less than the critical value at the $5 \%$ level of significance $\left[\chi^{2}(57)=75.62\right]$, the null hypothesis of exogeneity cannot be rejected.

Finally, the homotheticity hypothesis is tested applying a likelihood ratio test for each equation. The null hypothesis is clearly rejected since all the obtained values (309.29 for beef; 161.34 for pork; 454.21 for poultry; 242.60 for fish; and 122.96 for eggs) are well above the critical value at the $5 \%$ level of significance $\left[\chi^{2}(8)=15.51\right]$. Hence, we conclude that the levels of nutrients considered in this study do affect input shares.

Summing up, two main conclusions are obtained from these tests. First, the Spanish meat consumer makes two independent decisions: to purchase or not, and how much to purchase. Independency is an important economic conclusion since it implies that consumers decide whether to buy a product without considering how much they are going to purchase. Second, since the ITIP model is never dominated, we conclude that Spanish zero expenditure responses are due to a decision of no consumption based on main economic determinants (income or prices) or purchasing habits (some goods are bought monthly or every fifteen days 
and, then, it is possible that no record has been registered by the household during the week it was surveyed). ${ }^{15}$

\section{Elasticities}

The selected ITIP models can be specified as follows:

- Purchasing decision:

$$
\begin{aligned}
\mathrm{PD}_{\mathrm{i}}^{*} & =\alpha_{i}+\sum_{j} \alpha_{i j} \ln p_{j}+1 / 2 \sum_{k} \theta_{i k} \ln a+\gamma_{i} F E+\xi_{i} H S \\
& +\varsigma_{i} P C+v_{i} P Y+\psi_{i} P A+\sum_{e=1}^{3} l_{i} E_{e}+\sum_{t=1}^{3} \mu_{i} S T_{t}+\mathrm{u}_{\mathrm{i}}
\end{aligned},
$$

where $\mathrm{PD}_{\mathrm{i}}^{*}$ represents the latent participation variable for the $\mathrm{i}^{\text {th }}$ product; $F E$ represents the total per capita food expenditure; $H S$, the household size; $P C$, the percentage of members below the age of 14; $P Y$, the percentage of members aged between 14 and 29; $P A$, the percentage of members aged between 30 and 59; $E_{e}$ represents the three levels of education; and finally, $S T_{t}$ represents the three variables introduced to distinguish the size of the town in which the household lives.

- Expenditure decision:

$$
\begin{aligned}
w_{\mathrm{i}}^{*}= & \alpha_{i}^{\prime}+\sum_{j} \alpha_{i j}^{\prime} \ln p_{j}+1 / 2 \sum_{k} \theta_{i k}^{\prime} \ln a+\gamma_{i}^{\prime} F E+\xi_{i}^{\prime} H S \\
& +\varsigma_{i}^{\prime} P C+v_{i}^{\prime} P Y+\psi_{i}^{\prime} P A+\sum_{e=1}^{3} i_{i}^{\prime} E_{e}+\sum_{t=1}^{3} \mu_{i}^{\prime} S T_{t}+\mathrm{v}_{\mathrm{i}}
\end{aligned}
$$

where $\mathrm{w}_{\mathrm{i}}{ }_{\mathrm{i}}$ is the latent $\mathrm{i}^{\text {th }}$ product budget share, and the other variables are as defined above.

Finally, the error terms are independently and normally distributed:

$$
u_{i} \sim N(0,1) \text { and } v_{i} \sim N\left(0, \sigma_{i}^{2}\right) .
$$

The models are estimated by Maximum Likelihood. Estimated parameters (Table 6) have the expected signs and most of them are significant at the 5\% level. In any case, and for 
interpretation purposes, the most interesting indicators are the different demand elasticities that can be obtained from estimated parameters.

\section{(Insert Table 6)}

The first such elasticity is the so-called elasticity of participation. It measures the effect that a percentage change in one explanatory variable has on the likelihood of participating in the market. ${ }^{16}$ The second elasticity relates to the probability of consumption. It reflects the effect that a percentage change in one explanatory variable has on the probability of consumption. Next, we have the elasticity of the conditional level of consumption, which measures the effect that a percentage change in a variable has on consumption once the decision to consume has been made. Finally, we calculate the elasticity of the unconditional level of consumption or total elasticity, which provides an overall assessment of the effect changes in one variable on consumption. All elasticities with respect to all continuous variables, together with their respective standard errors, are calculated for all products at sample means. Results are presented in Table 7.

\section{(Insert Table 7)}

\section{Price and Income effects}

Although all own-price elasticities are negative, magnitudes differ considerably for the different types of elasticities. The elasticities of participation are much lower than the elasticities of the unconditional level of consumption. In other words, changes in own prices do not affect very much the decision to participate in the market. They mainly affect the quantity purchased. In this case, the demand for pork and poultry are the most elastic.

With regard to cross-price effects, Table 7 shows that most of the elasticities of participation are insignificant. The main exceptions are the positive relationships between changes in fish and pork prices and the probability of purchasing beef. The elasticities of the unconditional level of consumption show that fish and eggs are complementary goods whereas some substitutability exists between poultry with respect to beef and fish, as well as fish with respect to beef.

The elasticity of participation with respect to total food expenditure is positive for all 
products, reflecting the fact that when total food expenditure increases (decreases), the probability of purchase also increases (decreases). Considering now the elasticity of the unconditional level of consumption, beef and fish can be considered luxury products; the expenditure elasticity for pork is around unity; and finally, poultry and eggs are necessities. The decomposition of the elasticities of the unconditional level of consumption into its two components shows that changes in total food expenditure affect consumption mainly through the conditional level and not through the probability of consumption. That is, an increase in total food expenditure is not likely to induce many marginal consumers to consume meat, but additional sales will likely come from existing consumers.

\section{Nutritive value effects}

Table 7 shows that the probabilities of purchasing all considered products generally increase (decrease) when total protein, lipid and vitamin intake also increases (decreases). The opposite takes place with respect to total energy intake. In general terms, most of the elasticities are rather small, indicating that increasing total nutrient intake has a rather small impact on the probability of buying meat products. For the elasticities of the unconditional level of consumption, results are as expected. As mentioned in the introduction, meat products are the main suppliers of a higher-quality protein intake. Thus, the highest positive elasticity corresponds to protein. From this point of view an increase in the total protein intake will mainly benefit beef and poultry.

Analyzing the two components of this elasticity we can conclude that the increasing consumption of meat products due to an increase of the total protein intake will mainly come from existing consumers but also a significant increase of marginal consumers will take place. The elasticities of calcium and other minerals intake are negative, indicating that when the total intake of such nutrients increases consumers buy food products with a higher content of calcium and other minerals, and decrease meat consumption. Negative elasticities do not mean that meat products are undesirable. On the contrary, it means that other food products are more important suppliers of these specific nutrients, inducing consumers to increase the consumption of these products.

\section{Demographic effects}

The elasticities of participation are positive with respect to the size of the household for all products. Moreover, as the number of members within a household increases, the 
unconditional level of beef consumption also increases, while the consumption of the rest of the products do not significantly react to household size changes. As regards the elasticities of family composition (measured as the percentages of household members in several age categories), Table 7 shows that as the percentage of members between 14 and 59 increases, the probability of purchasing poultry also increases, while the probability of purchasing fish decreases. Similarly, the older the members of a household are, the lower the level of pork consumption and the higher the level of fish consumption.

Finally, the effects of the level of education and town size are analyzed. Since dummy variables have been defined to take these effects into account, marginal effects are calculated. The principal results from these analyzes are shown in Table 8. The level of education is positively related to the probability of purchasing beef and negatively related to the probability of purchasing pork. Households with higher level of education consume larger quantities of beef and fish, and less pork, poultry and eggs. Results also indicate that those living in the smallest towns (less than 50,000 inhabitants) are the least likely to purchase beef. Beef and fish consumption is higher in large towns (between 50,001 and 500,000 inhabitants) while more pork, poultry and eggs are consumed in smaller towns.

(Insert Table 8)

\section{Implicit prices}

As a final step in our study, and following Nerlove (1995), we derive implicit prices that Spanish consumers attach to the marginal unit of the different nutrients contained in the different products. Using calculated total price and nutrient elasticities together with sample mean values for per capita nutrient intake and prices, implicit prices adopt the following $\operatorname{expression}^{17}$ :

$$
\pi_{k}=-\frac{\frac{\partial E\left(q_{i}\right)}{\partial a_{k}}}{\frac{\partial E\left(q_{i}\right)}{\partial p_{i}}}=-\frac{\frac{\partial E\left(q_{i}\right)}{\partial a_{k}} \frac{a_{k}}{E\left(q_{i}\right)}}{\frac{\partial E\left(q_{i}\right)}{\partial p_{i}} \frac{p_{i}}{E\left(q_{i}\right)}} \frac{p_{i}}{a_{k}} \quad k=1, \ldots, r
$$

where $E\left(q_{i}\right)$ represents the unconditional level of consumption. 
Results are shown in Table 9. Not that negative marginal prices are consistent with the Consumer Goods Characteristic Model as some products attributes may be undesirable (Ladd and Suvannunt, 1976). Adding more of one of these characteristics to a specific product may reduce its value to consumers. In any case, in this study most negative values are close to zero and are related to nutrients, which are only contained marginally in meat products. As mentioned in the introduction, meat products are main providers of high quality proteins. From this point of view, Spanish consumers perceive beef as the highest quality meat in terms of protein intake and eggs as the lowest quality protein source. Implicit prices for proteins are similar for the other meat products.

(Insert Table 9)

Finally, to measure to what extent the demand elasticities are affected by the inclusion of nutrient values, we estimate a traditional Almost Ideal System (AIDS) model (Deaton and Muellbauer, 1980b), in the form of a ITIP model for comparison purposes, only including income, prices and household characteristics as main food demand determinants. Table 10 shows obtained results of the elasticity of participation and the elasticity of the unconditional level of consumption. Several tests have been performed in order to check if significant differences exist between these elasticities and those shown in Table 7. As can be observed in Table 11, the differences are significant in most cases. From the comparison of magnitudes obtained for both types of elasticities, it can be observed that greatest differences are observed with respect to expenditure elasticities. The elasticity of participation with respect to total food expenditure is substantially lower when nutrient values are included. Finally, the elasticity of the unconditional level of consumption increases for beef and fish when nutrients are included and decreases for the other products.

(Insert Tables 10 and 11)

\section{Concluding remarks}

In this paper, the demand for meat is analyzed taking into account its nutritional characteristics based on the assumption that, at least in more developed countries, nutrient intake is an increasingly important determinant of food demand. The model is constructed so that the consumer's utility function does not depend on meat quantities but is a function of 
nutrient intakes and other prepared food characteristics. Since these new utility function arguments are not directly available in the market, they are derived from several inputs using household production theory. Finally, non-observable characteristics such as taste or smell are indirectly considered in the final model by introducing the most relevant household socioeconomic characteristics.

In order to validate the model obtained, the Spanish demand for meat is analyzed using micro level data. Since a large number of zero responses were obtained, several censored regression models are used and formal tests have been carried out to select the model that best fits the data. From the estimated parameters, meat demand elasticities with respect to price, nutrient content, expenditure and the rest of the included demographic variables are derived.

Two main sets of results are obtained. First, from the selected models, we deduce that zero responses are mainly due to a rational decision not to consume, based either on economic factors or on purchasing habits. Second, from the calculated elasticities, the following principal implications are obtained: i) changes in own prices mainly affect the quantity of meat purchased and not the decision to purchase or not; ii) the probability of purchasing beef is positively related to changes in fish and pork prices; iii) fish and eggs are complementary goods while some substitutability exists between poultry with respect to beef and fish, as well as between fish and beef; iv) as regards nutrient intake, the highest positive unconditional elasticity corresponds to total protein intake; v) all considered products are more likely to be purchased as total food expenditure increases; vi) beef, fish and, less clearly, pork are luxuries while poultry and eggs are necessities; vii) the probability of purchasing all products as well as beef consumption increase with household size; viii) fish consumption increases as the members of a household get older; ix) there is a positive relationship between the education level of the head of household and the probability of purchasing beef as well as the consumption of beef and fish; and finally, $\mathrm{x}$ ) households living in large towns tend to consume more beef and fish.

The approach we employ can provide new insights into food consumption behavior. Moreover, it is important to note that the main advantage of the model that we propose, in comparison with alternatives presented in the literature, is not the possibility to obtain nutrient intake elasticities but to offer a new framework in which demand elasticities (income 
and prices) are determined by nutrient content. As demonstrated in last section, estimated demand elasticities differ substantially depending on whether or not nutrient variables are introduced.

Future research could be directed towards refining some of the econometric issues raised here. One of these issues concerns the exogeneity of the total expenditure and nutrient intake variables. Although in this paper the null of exogeneity is not rejected, it is not entirely clear that appropriate instruments have been used. Other instruments could be designed in the form of indexes to better cope with this problem.

\section{Achnowledgements}

We thank to the project SEC2002-02350 of the Plan Nacional de Investigación Científica, Desarrollo e Innovación Tecnológica, for financial support.

\section{REFERENCES}

Adrian, J., Daniel, R., 1976. Impact of the Socio-economic Factors on Consumption of selected Food Nutrients in the United States. American Journal of Agricultural Economics 58, 31-38.

Amemiya, T., 1984. Tobit models: a survey. Journal of Econometrics 24, 3-61.

Angulo, A.M., Gil, J.M., Gracia, A., 2001. The demand for alcoholic beverages in Spain. Agricultural Economics 26, 71-83.

Becker, G.S., 1965. A theory of the allocation of time. Economic Journal 75, 493-517.

Ben Kaabia, M., Angulo, A.M., Gil, J.M., 2001. Health Information and the Demand for Meat in Spain. European Review of Agricultural Economics 28(4), 499-517.

Blundell, R., Meghir, C., 1987. Bivariate Alternatives to the Tobit Model. Journal of Econometrics $34,179-200$.

Burton, M., Dorsett, R., Young, T., 1996. Changing Preferences for Meat: Evidence from UK household data, 1973-93. European Review of Agricultural Economics 23, 357-370.

Burton, M., Young, T., 1996. The impact of BSE on the demand for beef and other meats in Great Britain. Applied Economics 28, 687-693.

Capps, O., Jr. Schmitz, J.D., 1991. A recognition of health and nutrition factors in food demand analysis. Western Journal of Agricultural Economics 16, 21-35.

Clarke, K.A., 2003. Nonparametric Model Discrimination in International Relations. Journal of Conflict Resolution 47(1), 72-93. 
Chesher, A., 1998. Individual Demands from Household Aggregates: time and age variation in the composition of diet. Journal of Applied Econometrics 13, 505-524.

Cowling, R.G.D., Raynor, A.J., 1970. Price, quality and market shares. Journal of Political Economy 78, 1292-1309.

Cox, T.L., Wohlgenant, M.K., 1986. Prices and quality effects in cross-sectional demand analysis. American Journal of Agricultural Economics 68, 908-919.

Deaton, A., Muellbauer, J., 1980a. Economics and Consumer Behavior. Cambridge: Cambridge University Press.

Deaton, A., Muellbauer, J., 1980b. An Almost Ideal Demand System. American Economic Review $70,312-326$.

Gao, X.M., Wailes, E.J., Cramer, G.L., 1995. Double Hurdle model with bivariate normal errors: An application to U.S. rice demand. Journal of Agricultural and Applied Economics 27(2), 363-376.

Gao, X.M., Wailes, E.J., Cramer, G.L., 1997a. A Microeconometric Analysis of Consumer Taste Determination and Taste Change for Beef. American Journal of Agricultural Economics 79, 573582.

Gao, X.M., Richards, T.J., Kagan, A., 1997b. A latent variable model of consumer taste determination and taste change for complex carbohydrates. Applied Economics 29, 1643-1654.

Hausman, J.A., 1978. Specification Tests in Econometrics. Econometrica 46(6), 1251-1271.

Hayes, D.J., Wahl, T.I., Williams, G.W., 1990. Testing restrictions on a model of Japanese meat demand. American Journal of Agricultural Economics 72, 556-566.

Huang, K.S., 1999. Effects of food prices and Consumer Income on Nutrient Availability. Applied Economics 31 (3), 367-380.

INE, several years. Encuesta Continua de Presupuestos Familiares. Instituto nacional de Estadística, Madrid.

Kim, S., Chern, W.S., 1999. Alternative measures of health information and demand for fats and oils in Japan. Journal of Consumer Affairs 33, 92-109.

Kinnucan, H.W., Xiao, H., Hsia, C.J., Jackson, J.D., 1997. Effect of health information and generic advertising on U.S. Meat demand. American Journal of Agricultural Economics 79, 13-23.

Ladd, G.W., Suvannunt, V., 1976. A Model of Consumer Goods Characteristics. American Journal of Agricultural Economics 58(3), 504-510.

Lancaster, K., 1971. Consumer Demand: A New Approach. Columbia University Press, New York.

Lau, L., 1982. A note on the fundamental theorem of exact aggregation. Economics letters 9, 119-126.

Nayga, R.M., 1994. Effects of Socio-economic and Demographic Factors on Consumption of Selected Food Nutrients. Agricultural and Resource Economics Review, October, 171-182.

Nerlove, M., 1995. Hedonic price functions and the measurement of preferences: the case of Swedish wine consumers. European Economic Review 39, 1697-1716. 
Orcutt, G.H., Watts, H.W., Edwards, J.B., 1968. Data aggregation and information loss. American Economics Review 58, 773-787.

Pollak, R.A., Wales, T.J., 1981. Demographic variables in demand analysis. Econometrica 49(6), 1533-1558.

Pudney, S.E., 1981. An Empirical Method of Approximating the Separable Structure of Consumer Preferences. Review of Economic Studies 48, 561-578.

Ramezani, C.A., 1995. Determinants of Nutrient Demand: A Nonparametric Analysis. Journal of Agricultural and Resource Economics 20(1): 165-177.

Ramezani, C.A., Rose, D., Murphy, S., 1995. Aggregation, Flexible Forms, and Estimation of Food Consumption Parameters. American Journal of Agricultural Economics 77(3): 525-532.

Su, S.J.B. Yen, S.T., 1996. Microeconometric models of infrequently purchased goods: an application to household pork consumption. Empirical Economics 21: 513-533.

Subramanian, S., Deaton, A., 1996. The Demand for Food and Calories. Journal of Political Economy 104 (1): 133-162.

TSP International, 2005. Times Series Processor.

Vuong, Q.H., 1989. Likelihood ratio test for model selection and non-nested hypotheses. Econometrica 57: 307-333.

Wald, A., 1940. The fitting of straight lines if both variables are subject to errors. Annals of Mathematical statistics: 284-300.

Willett, W.C., 1994. Diet and Health: What should we eat?. Science 264: 532-537.

Xiao, Y., Taylor, J.E., 1995. The Impact of Income Growth on Farm Household Nutrient Intake: A Case Study of a Prosperous Rural Area in Northern China. Economic Development and Cultural Change 43(4): 805-819.

Yen, S.T., Jones, A.M., 1997. Household consumption of cheese: an inverse hyperbolic sine doublehurdle model with dependent errors. American Journal of Agricultural Economics 79: 246-251. 


\section{APPENDIX}

Assume that the purchase and expenditure decision components of the ITIP model are specified, respectively, as follows:

$$
\begin{array}{ll}
P D_{i}^{*}=z_{i} \alpha+u_{i} & \text { where } P D=1 \text { if } P D_{i}^{*}>0, \\
w_{\mathrm{i}}^{*}=\mathrm{x}_{\mathrm{i}} \beta+\mathrm{v}_{\mathrm{i}} & \text { where } w_{\mathrm{i}}=w_{\mathrm{i}}^{*} / \Phi\left(z_{i} \alpha\right) \text { if } \\
w_{i}^{*}>0 \text { and } P D_{i}^{*}>0 & \text { with } u_{i} \sim N(0,1) \text { and } v_{i} \sim N\left(0, \sigma_{i}^{2}\right) .
\end{array}
$$

1. The elasticity of participation is calculated from the marginal response of the participation probability and, based on the ITIP structure and normality assumptions of the error terms, it is equal to:

$$
\frac{\partial \mathrm{P}(P D=1)}{\partial_{\mathrm{Z}_{\mathrm{ij}}}} \frac{\mathrm{Z}_{\mathrm{ij}}}{\mathrm{P}(P D=1)}=\phi\left(\mathrm{z}_{\mathrm{i}} \alpha\right) \alpha_{\mathrm{j}} \frac{\mathrm{Z}_{\mathrm{ij}}}{\mathrm{P}(P D=1)}
$$

2. The elasticity of the probability of consumption is calculated from the marginal effect of $x_{i j}$ on the probability of consumption as follows:

$$
\frac{\partial \mathrm{P}\left(w_{\mathrm{i}}>0\right)}{\partial x_{\mathrm{ij}}} \frac{x_{\mathrm{ij}}}{\mathrm{P}\left(w_{\mathrm{i}}>0\right)}=\frac{\partial \Phi\left(\mathrm{zi}_{\mathrm{i}} \alpha\right) \Phi\left(\frac{x_{i} \beta}{\sigma_{i}}\right)}{\partial x_{\mathrm{ij}}} \frac{x_{\mathrm{ij}}}{\mathrm{P}\left(w_{\mathrm{i}}>0\right)} .
$$

3. The elasticity of the conditional level of consumption is calculated as follows:

$$
\frac{\partial E\left(q_{i} \mid q_{i}>0\right)}{\partial x_{i j}} \frac{x_{i j}}{E\left(q_{i} \mid q_{i}>0\right)},
$$

where $E\left(q_{i} \mid q_{i}>0\right)=E\left(w_{i} \mid w_{i}>0\right) \frac{C}{P_{i}}$,

and $E\left(w_{i} \mid w_{i}>0\right)=\Phi\left(z_{i} \alpha\right)\left[\Phi\left(\frac{x_{i} \beta}{\sigma_{i}}\right)\right]^{-1} \int_{0}^{\infty} w_{i} \frac{1}{\sigma_{i}} \varphi\left[\frac{\Phi\left(z_{i} \alpha\right) w_{i}-x_{i} \beta}{\sigma_{i}}\right] d w_{i}$.

4. The elasticity of the unconditional level of consumption or total elasticity is calculated as 
follows:

$$
\frac{\partial E\left(q_{i}\right)}{\partial x_{i j}} \frac{x_{i j}}{E\left(q_{i}\right)}=\frac{\partial P\left(w_{i}>0\right) E\left(q_{i} \mid q_{i}>0\right)}{\partial x_{i j}} \frac{x_{i j}}{E\left(q_{i}\right)} .
$$

Note that this elasticity is simply obtained by adding up the elasticity of the probability of consumption (2) and the elasticity of the conditional level of consumption (3). 
Table 1. Meat, fish and egg expenditure share in $1999(\%)$

\begin{tabular}{|c|c|c|c|c|c|}
\hline & Beef & Pork & Poultry & Fish & Eggs \\
\hline All sample & 9.12 & 6.42 & 6.71 & 11.54 & 2.66 \\
\hline \multicolumn{6}{|c|}{ Level of education of the head of houshold } \\
\hline Unschooled & 5.88 & 7.20 & 6.98 & 9.45 & 2.78 \\
\hline Primary school & 9.40 & 6.71 & 6.77 & 11.67 & 2.72 \\
\hline Secondary school & 18.84 & 5.69 & 6.72 & 12.53 & 2.52 \\
\hline Post secondary degree & 11.28 & 5.01 & 5.59 & 13.69 & 2.45 \\
\hline \multicolumn{6}{|l|}{ Size of the town } \\
\hline$<=10,000$ inhabitants & 7.41 & 7.98 & 6.81 & 10.42 & 2.83 \\
\hline $10,001-50,000$ & 7.83 & 7.30 & 6.83 & 10.56 & 2.67 \\
\hline $50,001-500,000$ & 10.62 & 5.31 & 6.33 & 12.23 & 2.55 \\
\hline More than 500,000 & 10.92 & 4.56 & 7.36 & 13.79 & 2.58 \\
\hline \multicolumn{6}{|l|}{ Houshold size } \\
\hline 1 member & 6.82 & 4.28 & 5.96 & 10.56 & 2.55 \\
\hline 2 members & 9.15 & 5.34 & 6.76 & 12.54 & 2.63 \\
\hline 3 members & 9.40 & 6.51 & 6.57 & 11.99 & 2.53 \\
\hline 4 members & 9.77 & 7.39 & 6.70 & 11.26 & 2.66 \\
\hline 5 members & 8.96 & 8.04 & 7.46 & 10.93 & 2.79 \\
\hline More than 5 members & 9.31 & 6.78 & 6.90 & 9.89 & 3.23 \\
\hline \multicolumn{6}{|l|}{ Age } \\
\hline \multicolumn{6}{|c|}{ Age of the head of household } \\
\hline$<=29$ years old & 8.52 & 6.98 & 6.87 & 8.45 & 2.95 \\
\hline $30-45$ years old & 9.39 & 6.44 & 6.75 & 11.69 & 2.48 \\
\hline $46-60$ years old & 9.72 & 7.37 & 6.79 & 11.65 & 2.82 \\
\hline$>60$ years & 8.46 & 5.55 & 6.60 & 11.65 & 2.64 \\
\hline \multicolumn{6}{|l|}{ Family composition } \\
\hline \multicolumn{6}{|c|}{ \% of members less than 14 years old } \\
\hline $0-25 \%$ & 9.11 & 6.14 & 6.61 & 11.70 & 2.70 \\
\hline $25-50 \%$ & 9.62 & 7.17 & 6.76 & 11.32 & 2.55 \\
\hline $50-75 \%$ & 8.42 & 7.22 & 7.32 & 10.83 & 2.55 \\
\hline More than $75 \%$ & - & - & - & - & - \\
\hline \multicolumn{6}{|c|}{ \% of members from 14 to 29 years old } \\
\hline $0-25 \%$ & 8.79 & 5.70 & 6.73 & 11.91 & 2.57 \\
\hline $25-50 \%$ & 9.36 & 7.71 & 6.53 & 11.20 & 2.58 \\
\hline $50-75 \%$ & 9.66 & 6.86 & 6.91 & 11.15 & 2.95 \\
\hline More than $75 \%$ & 9.68 & 6.79 & 6.02 & 9.08 & 3.02 \\
\hline \multicolumn{6}{|c|}{$\%$ of members from 30 to 59 years old } \\
\hline $0-25 \%$ & 7.97 & 5.85 & 6.64 & 11.37 & 2.60 \\
\hline $25-50 \%$ & 8.63 & 7.15 & 7.19 & 11.21 & 2.86 \\
\hline $50-75 \%$ & 10.58 & 6.57 & 6.54 & 11.80 & 2.56 \\
\hline More than $75 \%$ & 7.81 & 5.24 & 6.15 & 12.26 & 2.79 \\
\hline \multicolumn{6}{|c|}{$\%$ of members 60 years old and older } \\
\hline $0-25 \%$ & 9.45 & 6.86 & 6.85 & 11.32 & 2.70 \\
\hline $25-50 \%$ & 8.97 & 7.20 & 5.95 & 11.97 & 2.86 \\
\hline $50-75 \%$ & 9.90 & 6.13 & 6.65 & 11.56 & 2.58 \\
\hline More than $75 \%$ & 7.85 & 5.04 & 6.68 & 11.98 & 2.53 \\
\hline
\end{tabular}

Source: Authors' calculations using the Spanish Quarterly Household National Expenditure Survey. 
Table 2. The contribution of meat, fish and eggs to total nutrient intake in $1999(\%)$

\begin{tabular}{l|ccccc|c}
\hline & Beef & Pork & Poultry & Fish & Eggs & Total \\
\hline Energy & 4.22 & 3.55 & 3.67 & 2.06 & 2.35 & 15.85 \\
Proteins & 8.10 & 6.50 & 12.97 & 10.60 & 6.02 & 44.19 \\
Carbohydrates & - & - & - & 0.14 & - & 0.14 \\
Lipids & 8.26 & 7.41 & 5.46 & 1.68 & 4.55 & 27.36 \\
Vitamins & 0.66 & 0.45 & 1.02 & 3.58 & 6.29 & 12 \\
Fibre & - & - & - & - & - & - \\
Calcium & 0.40 & 0.39 & 0.99 & 2.45 & 2.73 & 6.96 \\
Other minerals & 2.85 & 2.20 & 4.10 & 4.96 & 1.93 & 16.04 \\
\hline
\end{tabular}

Source: Authors' calculations using the Spanish Quarterly Household National Expenditure Survey.

Table 3. Maximum log likelihood values and likelihood ratio (LR) tests for heteroscedastic errors $^{(a)}$

\begin{tabular}{lcccccc}
\hline & & & & & & \\
& & Beef & Pork & Poultry & Fish & Eggs \\
\hline Simultaneous & Homosc. & -1196.4 & -1666.1 & -2771.1 & -1862.3 & -3774.8 \\
Infrequency of & Heterosc. & -1164.9 & -1653.5 & -2733.2 & -1789.1 & -3760.9 \\
Purchase (SIP) & LR & $62.92^{*}$ & $25.1^{*}$ & $75.8^{*}$ & $146.42^{*}$ & $27.72^{*}$ \\
\hline Independent & Homosc. & -1056.3 & -1532.1 & -2571.7 & -1701.3 & -3607.9 \\
Infrequency of & Heterosc. & -968.3 & -1455.7 & -2531.9 & -1580.9 & -3578.3 \\
Purchase (IIP) & LR & $176.0^{*}$ & $152.8^{*}$ & $79.7^{*}$ & $240.8^{*}$ & $59.1 *$ \\
\hline Simultaneous Tobit- & Homosc. & -1001.0 & -1409.0 & -2618.5 & -1806.4 & -3635.5 \\
Infrequency of & Heterosc. & -923.0 & -1352.8 & -2588.5 & -1677.8 & -3627.2 \\
Purchase (STIP) & LR & $156.1^{*}$ & $112.5^{*}$ & $60.1^{*}$ & $257.2^{*}$ & $16.4 *$ \\
\hline Independent Tobit- & Homosc. & -774.5 & -1196.8 & -2406.1 & -1546.4 & -3449.7 \\
Infrequency of & Heterosc. & -747.8 & -1174.0 & -2391.3 & -1469.7 & -3432.1 \\
Purchase (ITIP) & LR & $53.4^{*}$ & $45.5^{*}$ & $29.6^{*}$ & $153.5^{*}$ & $35.2^{*}$ \\
\hline Simultaneous & Homosc. & -1192.9 & -1589.4 & -2696.6 & -1837.4 & -3705.4 \\
Double Hurdle & Heterosc. & -1123.6 & -1560.0 & -2676.2 & -1762.0 & -3690.8 \\
(SDH) & LR & $138.6 *$ & $59.0^{*}$ & $40.8^{*}$ & $150.8^{*}$ & $29.2^{*}$ \\
\hline Independent Double & Homosc. & -844.2 & -1432.9 & -2516.7 & -1631.0 & -3765.7 \\
Hurdle (IDH) & Heterosc. & -803.3 & -1366.2 & -2479.1 & -1552.6 & -3654.6 \\
& LR & $81.8^{*}$ & $133.4^{*}$ & $75.2^{*}$ & $156.9^{*}$ & $222.2^{*}$ \\
\hline I An ast
\end{tabular}

(a) An asterisk indicates that the null hypothesis of homoscedastic error is rejected at the 5\% level. The corresponding critical value is $\chi^{2}(4)=9.49$. 
Table 4. Vuong test for model selection ${ }^{(a)}$

\begin{tabular}{|c|c|c|c|c|c|}
\hline & Beef & Pork & Poultry & Fish & Eggs \\
\hline SIP- IIP ${ }^{(b)}$ & $-7.10^{*}$ & $-7.81 *$ & $-8.30 *$ & $-9.21 *$ & $-6.92 *$ \\
\hline Selected model & IIP & IIP & IIP & IIP & IIP \\
\hline STIP- ITIP $^{(b)}$ & $-6.95 *$ & $-7.10 *$ & $-9.10^{*}$ & $-9.42 *$ & $-8.92 *$ \\
\hline Selected model & ITIP & ITIP & ITIP & ITIP & ITIP \\
\hline SDH- IDH ${ }^{(\mathrm{b})}$ & $-13.86^{*}$ & $-8.57 *$ & $-9.32 *$ & $-9.69 *$ & $-4.25^{*}$ \\
\hline Selected model & IDH & IDH & IDH & IDH & IDH \\
\hline ITIP- IIP $^{(b)}$ & $12.41^{*}$ & $13.24 *$ & $4.95 *$ & $6.60 *$ & $6.98^{*}$ \\
\hline Selected model & ITIP & ITIP & ITIP & ITIP & ITIP \\
\hline $\begin{array}{l}\text { Previous selected model- } \\
\text { IDH }^{(b)}\end{array}$ & 0.06 & $2.03 *$ & 1.37 & 1.80 & $2.46^{*}$ \\
\hline Selected model & $\begin{array}{l}\text { ITIP / } \\
\text { IDH }\end{array}$ & ITIP & $\begin{array}{c}\text { ITIP / } \\
\text { IDH }\end{array}$ & $\begin{array}{l}\text { ITIP / } \\
\text { IDH }\end{array}$ & ITIP \\
\hline
\end{tabular}

(a) STIP denotes the Simultaneous Tobit-Infrequency of Purchase Model; ITIP denotes the Independent Tobit-Infrequency of Purchase Model; SIP denotes the Simultaneous Infrequency of Purchase model; IIP denotes the Independent Infrequency of Purchase model; SDH represents the Simultaneous Double Hurdle Model; IDH represents the Independent Double Hurdle Model. In all models, heteroscedasticity is considered.

(b) An asterisk inconjunction with a positive value indicates that the null hypothesis is rejected at the 5\% level, that is, the first model is preferred. An asterisk in conjunction with a negative value indicates that the second model is preferred. Otherwise, both models are equally valid. 
Table 5. Clarke test for model selection ${ }^{(a)}$

\begin{tabular}{|c|c|c|c|c|}
\hline & \multicolumn{2}{|c|}{ One-sided tests } & \multirow{2}{*}{$\begin{array}{l}\text { Two-sided test } \\
\text { Ha: median of model } \\
\text { ITIP - IDH } \neq 0\end{array}$} & \multirow{2}{*}{$\begin{array}{l}\text { Selected } \\
\text { model }\end{array}$} \\
\hline & $\begin{array}{l}\text { Ha: median of model } \\
\text { ITIP - IDH >0 }\end{array}$ & $\begin{array}{l}\text { Ha: median of model } \\
\text { ITIP - IDH < } 0\end{array}$ & & \\
\hline Beef & $\begin{array}{c}\operatorname{Binomial}(\mathrm{n}=1657, \mathrm{x}>=852 \\
\mathrm{p}=0.5)=0.1292\end{array}$ & $\begin{array}{c}\operatorname{Binomial}(\mathrm{n}=1657, \mathrm{x}>= \\
805, \mathrm{p}=0.5)=0.8808\end{array}$ & $\begin{array}{c}\operatorname{Min}(1,2 * \operatorname{Binomial}(\mathrm{n}=1657, \mathrm{x} \\
>=852, \mathrm{p}=0.5))=0.2584\end{array}$ & $\begin{array}{l}\text { ITIP / } \\
\text { IDH }\end{array}$ \\
\hline Pork & $\begin{array}{c}\text { Binomial }(n=1656, x>=959 \\
p=0.5)=0.0000\end{array}$ & $\begin{array}{c}\text { Binomial }(n=1656, x>= \\
697, p=0.5)=1.0000\end{array}$ & $\begin{array}{c}\operatorname{Min}(1,2 * \operatorname{Binomial}(\mathrm{n}=1656, \mathrm{x} \\
>=959, \mathrm{p}=0.5))=0.0000\end{array}$ & ITIP \\
\hline Poultry & $\begin{array}{l}\operatorname{Binomial}(\mathrm{n}=1657, \mathrm{x}>= \\
1029, \mathrm{p}=0.5)=0.0000\end{array}$ & $\begin{array}{c}\text { Binomial }(\mathrm{n}=1657, \mathrm{x}>= \\
628, \mathrm{p}=0.5)=1.0000\end{array}$ & $\begin{array}{c}\operatorname{Min}(1,2 * \operatorname{Binomial}(\mathrm{n}=1657, \mathrm{x} \\
>=1029, \mathrm{p}=0.5))=0.0000\end{array}$ & ITIP \\
\hline Fish & $\begin{array}{c}\text { Binomial }(n=1657, x>=889 \\
p=0.5)=0.0016\end{array}$ & $\begin{array}{c}\text { Binomial }(n=1657, x>= \\
768, p=0.5)=0.9986\end{array}$ & $\begin{array}{c}\operatorname{Min}(1,2 * \operatorname{Binomial}(\mathrm{n}=1657, \mathrm{x} \\
>=889, \mathrm{p}=0.5))=0.0032\end{array}$ & ITIP \\
\hline Eggs & $\begin{array}{c}\text { Binomial }(\mathrm{n}=1657, \mathrm{x}>=990 \\
\mathrm{p}=0.5)=0.0000\end{array}$ & $\begin{array}{c}\text { Binomial }(n=1657, x>= \\
667, p=0.5)=1.0000\end{array}$ & $\begin{array}{c}\operatorname{Min}(1,2 * \operatorname{Binomial}(\mathrm{n}=1657, \mathrm{x} \\
>=990, \mathrm{p}=0.5))=0.0000\end{array}$ & ITIP \\
\hline
\end{tabular}

(a) ITIP denotes the Independent Tobit-Infrequency of Purchase Model and IDH represents the Independent Double Hurdle Model. In both models, heteroscedasticity is considered. 
Table 6. Estimated parameters for the selected ITIP models

Purchase equation parameters

\begin{tabular}{lccccc}
\hline & Beef & Pork & Poultry & Fish & Eggs \\
\hline Intercept & $-4.278^{*}$ & $-10.962^{*}$ & $5.923^{*}$ & $25.666^{*}$ & $11.478^{*}$ \\
Price of beef & $-0.871^{*}$ & 0.046 & 0.182 & -0.203 & -0.207 \\
Price of pork & $0.705^{*}$ & $-0.374^{*}$ & -0.382 & $0.767^{*}$ & 0.162 \\
Price of poultry & 0.061 & 0.012 & $-0.828^{*}$ & $0.730^{*}$ & 0.003 \\
Price of fish & $0.733^{*}$ & 0.009 & 0.107 & $-0.532^{*}$ & -0.357 \\
Price of eggs & 0.141 & -0.405 & -0.708 & -0.942 & 0.034 \\
Price rest of foods & 0.442 & $1.597^{*}$ & 0.167 & $-1.370^{*}$ & $-1.504^{*}$ \\
Energy & $-4.822^{*}$ & $-2.774^{*}$ & $-4.820^{*}$ & $-6.494^{*}$ & 0.407 \\
Proteins & 0.923 & $3.618^{*}$ & $-10.732^{*}$ & $4.840^{*}$ & -0.775 \\
Carbohydrates & 0.738 & 0.430 & $1.788^{*}$ & 0.149 & 0.026 \\
Lipids & $1.952^{*}$ & 0.323 & $1.946^{*}$ & $1.632^{*}$ & -0.476 \\
Vitamin & 0.720 & $1.304^{*}$ & $2.465^{*}$ & $3.011^{*}$ & -0.837 \\
Fibre & $1.255^{*}$ & -1.883 & $-5.174^{*}$ & -0.249 & 0.151 \\
Calcium & 0.327 & 0.106 & -0.557 & -0.528 & -0.336 \\
Other minerals & 0.447 & 0.729 & $12.657^{*}$ & $-5.551^{*}$ & 0.931 \\
Expenditure & 0.000 & 0.000 & $0.000^{*}$ & $0.000^{*}$ & $0.001^{*}$ \\
Household size & $0.164^{*}$ & $0.281^{*}$ & $0.334^{*}$ & $0.826^{*}$ & $0.289^{*}$ \\
$\%$ members $<14$ years & 0.192 & -0.054 & 0.237 & -0.582 & -0.009 \\
\% members 14-29 years & -0.079 & 0.173 & $1.733^{*}$ & $-1.108^{*}$ & 0.049 \\
\% members 30-59 years & -0.182 & 0.099 & $0.879^{*}$ & $-0.983^{*}$ & $-0.844^{*}$ \\
Primary school & 0.146 & 0.167 & -0.194 & $-0.420^{*}$ & 0.073 \\
Secondary school & 0.335 & 0.289 & 0.462 & 0.001 & 0.273 \\
Post secondary degree & $0.695^{*}$ & -0.118 & -0.508 & $-0.883^{*}$ & 0.079 \\
$\leq 10,000$ inhabitants & $-0.471^{*}$ & -0.060 & 0.320 & 0.079 & $-0.637^{*}$ \\
10,001-50,000 inhabit & $-0.367^{*}$ & 0.063 & -0.302 & -0.076 & -0.485 \\
50,001-500,000 inhabit & -0.266 & 0.031 & -0.084 & -0.083 & -0.398 \\
\hline & & & & & \\
\hline
\end{tabular}


Table 6 continued..

Expenditure equation parameters

\begin{tabular}{lccccc}
\hline & Beef & Pork & Poultry & Fish & Eggs \\
\hline Intercept & $0.699^{*}$ & $0.527^{*}$ & 0.069 & 0.325 & 0.015 \\
Price of beef & $0.048^{*}$ & $-0.019^{*}$ & -0.005 & -0.004 & -0.001 \\
Price of pork & $0.020^{*}$ & $0.018^{*}$ & 0.003 & 0.009 & 0.001 \\
Price of poultry & $0.023^{*}$ & 0.000 & $0.017^{*}$ & $0.019^{*}$ & 0.002 \\
Price of fish & $0.029^{*}$ & -0.007 & $-0.008^{*}$ & $0.047^{*}$ & $-0.006^{*}$ \\
Price of eggs & 0.019 & -0.001 & 0.001 & 0.011 & $0.014^{*}$ \\
Price rest of foods & $-0.115^{*}$ & $-0.078^{*}$ & -0.004 & $-0.045^{*}$ & $-0.012^{*}$ \\
Energy & -0.081 & 0.029 & -0.010 & $-0.100^{*}$ & -0.013 \\
Proteins & $0.360^{*}$ & $0.178^{*}$ & $0.311^{*}$ & $0.258^{*}$ & $0.050^{*}$ \\
Carbohydrates & $-0.099^{*}$ & -0.016 & -0.007 & $-0.059^{*}$ & $0.027^{*}$ \\
Lipids & $0.061^{*}$ & 0.003 & -0.007 & 0.021 & 0.007 \\
Vitamin & $-0.101^{*}$ & -0.002 & 0.014 & $0.066^{*}$ & $0.031^{*}$ \\
Fibre & $0.106^{*}$ & -0.005 & $0.052^{*}$ & -0.011 & $-0.015^{*}$ \\
Calcium & $-0.035^{*}$ & $-0.077^{*}$ & $-0.039^{*}$ & $-0.067^{*}$ & $-0.015^{*}$ \\
Other minerals & $-0.304^{*}$ & $-0.092^{*}$ & $-0.241^{*}$ & $-0.160^{*}$ & $-0.053^{*}$ \\
Expenditure & $0.001^{*}$ & 0.000 & $0.000^{*}$ & $0.001^{*}$ & $0.001^{*}$ \\
Household size & $0.010^{*}$ & 0.001 & -0.001 & 0.003 & 0.000 \\
$\%$ members < 14 years & $-0.026^{*}$ & $0.045^{*}$ & 0.011 & $-0.043^{*}$ & -0.004 \\
$\%$ members 14-29 years & -0.018 & $0.048^{*}$ & 0.002 & $-0.033^{*}$ & 0.002 \\
$\%$ members 30-59 years & 0.015 & $0.018^{*}$ & -0.005 & -0.009 & -0.001 \\
Primary school & $0.027^{*}$ & -0.004 & $-0.009^{*}$ & 0.005 & 0.001 \\
Secondary school & $0.041^{*}$ & $-0.019^{*}$ & $-0.008^{*}$ & $0.013^{*}$ & -0.002 \\
Post secondary degree & $0.038^{*}$ & $-0.013^{*}$ & $-0.012^{*}$ & $0.023^{*}$ & 0.000 \\
$\leq 10,000$ inhabitants & $-0.022^{*}$ & $0.017^{*}$ & $-0.008^{*}$ & -0.009 & -0.001 \\
10,001-50,000 inhabit. & -0.012 & $0.017^{*}$ & -0.005 & $-0.013^{*}$ & 0.000 \\
$50,001-500,000$ inhabit. & 0.004 & 0.001 & $-0.008^{*}$ & -0.004 & -0.001 \\
\hline & & & & &
\end{tabular}

Heterocedasticity parameters

\begin{tabular}{lccccc}
\hline & Beef & Pork & Poultry & Fish & Eggs \\
\hline Intercept & 1.048 & $-1.679^{*}$ & -0.046 & $6.351^{*}$ & $-7.254^{*}$ \\
Expenditure & $0.001^{*}$ & 0.000 & $0.000^{*}$ & $0.001^{*}$ & $0.001^{*}$ \\
Energy & $-0.922^{*}$ & $-1.080^{*}$ & $-0.518^{*}$ & $-1.589^{*}$ & $0.404^{*}$ \\
Lipids & $0.225^{*}$ & $0.323^{*}$ & 0.038 & $0.459^{*}$ & $-0.287^{*}$ \\
Proteins & $0.588^{*}$ & $1.070^{*}$ & $0.261^{*}$ & $0.588^{*}$ & 0.156 \\
\hline
\end{tabular}

* significant at the 5\% level. 
Table 7. Elasticities with respect to the continuous variables, calculated at mean values

\begin{tabular}{|c|c|c|c|c|c|c|c|c|c|c|c|c|c|c|c|c|c|c|c|c|}
\hline & \multicolumn{5}{|c|}{ Elasticity of participation } & \multicolumn{5}{|c|}{$\begin{array}{l}\text { Elasticity of probability of } \\
\text { consumption }\end{array}$} & \multicolumn{5}{|c|}{$\begin{array}{c}\text { Elasticity of the conditional } \\
\text { level of consumption }\end{array}$} & \multicolumn{5}{|c|}{$\begin{array}{l}\text { Elasticity of the unconditional } \\
\text { level of consumption }\end{array}$} \\
\hline & Beef & Pork & $\begin{array}{c}\text { Poul } \\
\text { try }\end{array}$ & Fish & Eggs & Beef & Pork & $\begin{array}{l}\text { Poul } \\
\text { try }\end{array}$ & Fish & Eggs & Beef & Pork & $\begin{array}{c}\text { Poul } \\
\text { try }\end{array}$ & Fish & Eggs & Beef & Pork & $\begin{array}{c}\text { Poul } \\
\text { try }\end{array}$ & Fish & Eggs \\
\hline Price of beef & $-0.12 *$ & 0.003 & 0.0003 & -0.001 & -0.0001 & 0.05 & $-0.09 *$ & -0.02 & -0.01 & -0.008 & $-0.57 *$ & $-0.17^{*}$ & -0.06 & -0.03 & -0.02 & $-0.52 *$ & $-0.26^{*}$ & -0.08 & -0.04 & -0.03 \\
\hline Price of pork & $0.10^{*}$ & -0.02 & -0.001 & $0.002 *$ & 0.0001 & $0.17 *$ & $0.06 *$ & 0.009 & 0.02 & 0.01 & 0.03 & $-0.82^{*}$ & 0.04 & 0.06 & 0.03 & 0.20 & $-0.76^{*}$ & 0.05 & 0.08 & 0.04 \\
\hline Price of poultry & 0.01 & 0.001 & $-0.001 *$ & $0.002 *$ & 0.000 & $0.09 *$ & 0.001 & $0.05^{*}$ & $0.03^{*}$ & 0.02 & $0.14^{*}$ & -0.001 & $-0.80 *$ & $0.12^{*}$ & 0.07 & $0.23 *$ & 0.000 & $-0.75^{*}$ & $0.15^{*}$ & 0.09 \\
\hline Price of fish & $0.10^{*}$ & 0.001 & 0.0002 & $-0.001^{*}$ & -0.0001 & $0.21 *$ & -0.04 & $-\overline{-}$ & $0.07^{*}$ & $-0.05^{*}$ & 0.08 & -0.06 & $-0.09 *$ & $-0.69 *$ & $-0.16^{*}$ & $0.29 *$ & -0.10 & -0.11 & $-0.62 *$ & $-0.21 *$ \\
\hline Price of eggs & 0.02 & -0.03 & -0.001 & -0.002 & 0.000 & 0.09 & -0.03 & 0.002 & 0.02 & $0.12^{*}$ & 0.10 & 0.01 & 0.02 & 0.07 & $-0.63^{*}$ & 0.19 & -0.02 & 0.02 & 0.09 & $-0.51 *$ \\
\hline $\begin{array}{l}\text { Price rest of } \\
\text { foods }\end{array}$ & 0.06 & $0.11 *$ & 0.0003 & $-0.003^{*}$ & $-0.001 *$ & $-0.35 *$ & $-0.28 *$ & -0.01 & $-0.08 *$ & $-0.11 *$ & $-0.81 *$ & $-0.78^{*}$ & -0.05 & $-0.30 *$ & $-0.34 *$ & $-1.16^{*}$ & $-1.06^{*}$ & -0.06 & $-0.38^{*}$ & $-0.45^{*}$ \\
\hline Energy & $-0.34 *$ & $-0.09 *$ & $-0.005^{*}$ & $-0.007^{*}$ & 0.0001 & -0.21 & $0.29 *$ & 0.07 & $0.20 *$ & $-0.15^{*}$ & -0.35 & -0.33 & -0.18 & $-0.72 *$ & -0.05 & -0.56 & -0.04 & -0.11 & $-0.52 *$ & -0.20 \\
\hline Proteins & 0.06 & $0.12 *$ & $-0.01 *$ & $0.006^{*}$ & -0.0001 & $0.53 *$ & $0.26^{*}$ & $0.38^{*}$ & $0.11^{*}$ & $0.19^{*}$ & $1.37 *$ & $1.19^{*}$ & $1.94 *$ & $1.00^{*}$ & $0.73^{*}$ & $1.90^{*}$ & $1.45^{*}$ & $2.32^{*}$ & $1.11^{*}$ & $0.92 *$ \\
\hline Carbohydrates & 0.05 & 0.01 & 0.002 & 0.0002 & 0.000 & -0.12 & -0.03 & $-\overline{-}$ & $-0.05 *$ & $0.12 *$ & $-0.37 *$ & -0.08 & -0.04 & $-0.20 *$ & $0.37 *$ & $-0.49 *$ & -0.11 & -0.05 & $-0.25^{*}$ & $0.49 *$ \\
\hline Lipids & $0.14^{*}$ & 0.01 & $0.002 *$ & $0.002^{*}$ & -0.0001 & $0.18^{*}$ & -0.07 & -0.02 & $-0.06^{*}$ & $0.09 *$ & $0.16^{*}$ & $0.16^{*}$ & -0.04 & $0.18^{*}$ & -0.003 & $0.34 *$ & 0.09 & -0.06 & 0.12 & 0.09 \\
\hline Vitamin & 0.05 & $0.04 *$ & $0.002 *$ & $0.004 *$ & -0.0001 & $-0.13 *$ & 0.04 & 0.02 & $0.06^{*}$ & $0.14 *$ & $-0.38^{*}$ & -0.05 & 0.08 & $0.22 *$ & $0.43^{*}$ & $-0.51 *$ & -0.01 & 0.10 & $0.28 *$ & $0.57^{*}$ \\
\hline Fibre & 0.09 & -0.06 & $-0.005^{*}$ & -0.0003 & 0.000 & $0.28 *$ & -0.07 & $0.07 *$ & -0.009 & $-0.07 *$ & $0.25^{*}$ & 0.05 & $0.32^{*}$ & -0.03 & $-0.21^{*}$ & $0.53 *$ & -0.02 & $0.39^{*}$ & -0.04 & $-0.28 *$ \\
\hline Calcium & 0.02 & 0.004 & -0.0005 & -0.0006 & -0.000 & -0.04 & $-0.19 *$ & $-\overline{-}$ & $-0.05 *$ & $-0.07 *$ & $-0.14 *$ & $-0.34 *$ & $-0.23 *$ & $-0.22 *$ & $-0.21 *$ & $-0.18 *$ & $-0.53 *$ & $-0.29 *$ & $-0.27 *$ & $-0.28 *$ \\
\hline Other minerals & 0.03 & 0.02 & $0.012 *$ & $-0.006^{*}$ & 0.0001 & $-0.51 *$ & -0.21 & $-\overline{-}$ & $-0.13 *$ & $-0.24 *$ & $-1.01 *$ & $-0.42 *$ & $-1.45^{*}$ & $-0.52 *$ & $-0.72 *$ & $-1.52 *$ & $-0.63 *$ & $-1.78^{*}$ & $-0.65^{*}$ & $-0.96 *$ \\
\hline Expenditure & 0.03 & 0.04 & $0.006^{*}$ & $0.009 *$ & $0.001 *$ & $0.20 *$ & 0.03 & $-\overline{-}^{-}$ & -0.02 & -0.03 & $1.53^{*}$ & $0.98 *$ & $0.71 *$ & $1.26^{*}$ & $0.73^{*}$ & $1.73^{*}$ & $1.01^{*}$ & $0.60 *$ & $1.24 *$ & $0.70^{*}$ \\
\hline Household size & $0.08^{*}$ & $0.06^{*}$ & $0.002 *$ & $0.006^{*}$ & $0.001 *$ & $0.19 *$ & $0.08 *$ & -0.01 & $0.02 *$ & 0.01 & $0.13^{*}$ & -0.03 & -0.05 & 0.06 & 0.03 & $0.32 *$ & 0.05 & -0.06 & 0.08 & 0.04 \\
\hline $\begin{array}{l}\% \text { members }<14 \\
\text { years }\end{array}$ & 0.003 & -0.001 & 0.0001 & -0.0001 & -0.000 & -0.008 & $0.03 *$ & 0.01 & $-0.01 *$ & -0.01 & -0.02 & $0.04 *$ & 0.01 & $-0.03^{*}$ & -0.01 & -0.03 & $0.07 *$ & 0.02 & $-0.04 *$ & -0.02 \\
\hline $\begin{array}{l}\% \text { members } 14- \\
29 \text { years }\end{array}$ & -0.002 & 0.002 & $0.001 *$ & $-0.001^{*}$ & 0.000 & -0.02 & $0.05^{*}$ & 0.002 & $-0.01 *$ & 0.01 & -0.02 & $0.08^{*}$ & 0.004 & $-0.05^{*}$ & 0.01 & -0.04 & $0.13^{*}$ & 0.006 & $-0.06^{*}$ & 0.02 \\
\hline
\end{tabular}




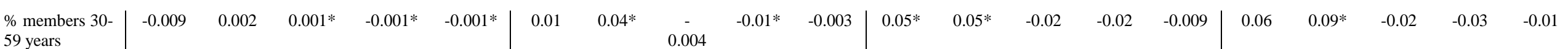
*Significant at the 5\% level 
Table 8. Effects with respect to the discrete variables, calculated at mean values

\begin{tabular}{|c|c|c|c|c|c|c|c|c|c|c|c|c|c|c|c|c|c|c|c|c|}
\hline & \multicolumn{5}{|c|}{ Effect on participation } & \multicolumn{5}{|c|}{$\begin{array}{l}\text { Effect on the probability of } \\
\text { consumption }\end{array}$} & \multicolumn{5}{|c|}{$\begin{array}{l}\text { Effects on the conditional level of } \\
\text { consumption }\end{array}$} & \multicolumn{5}{|c|}{$\begin{array}{l}\text { Effects on the unconditional level } \\
\text { of consumption }\end{array}$} \\
\hline & Beef & Pork & $\begin{array}{c}\text { Poul- } \\
\text { try }\end{array}$ & Fish & Eggs & Beef & Pork & $\begin{array}{c}\text { Poul- } \\
\text { try }\end{array}$ & Fish & Eggs & Beef & Pork & $\begin{array}{c}\text { Poul- } \\
\text { try }\end{array}$ & Fish & Eggs & Beef & Pork & $\begin{array}{c}\text { Poul- } \\
\text { try }\end{array}$ & Fish & Eggs \\
\hline \multicolumn{21}{|c|}{ Level of education ${ }^{\text {(a) }}$} \\
\hline $\begin{array}{l}\text { Primary } \\
\text { school }\end{array}$ & 0.016 & 0.021 & -0.001 & 0.000 & 0.000 & 0.045 & 0.039 & 0.004 & 0.012 & 0.016 & 0.418 & 0.467 & -0.027 & -0.446 & 2.563 & 0.036 & 0.119 & -0.008 & -0.080 & 2.742 \\
\hline $\begin{array}{l}\text { Secondary } \\
\text { school }\end{array}$ & 0.002 & 0.002 & 0.001 & 0.000 & -0.001 & 0.064 & -0.002 & -0.004 & -0.009 & -0.017 & 0.824 & -0.357 & -0.435 & 0.851 & -4.241 & 0.209 & -0.360 & -0.339 & -0.407 & -4.098 \\
\hline $\begin{array}{l}\text { Post } \\
\text { secondary } \\
\text { degree }\end{array}$ & 0.044 & -0.046 & -0.000 & -0.002 & -0.001 & 0.088 & -0.214 & -0.077 & 0.006 & -0.009 & 0.383 & -0.335 & -0.356 & 0.149 & -3.008 & 0.098 & -0.305 & -0.412 & 0.044 & -2.992 \\
\hline \multicolumn{21}{|c|}{ Size of the town where the household lives (number of inhabitants) ${ }^{(b)}$} \\
\hline$\leq 10,000$ & -0.056 & 0.001 & 0.001 & 0.001 & 0.000 & -0.141 & 0.089 & 0.012 & -0.006 & 0.003 & -0.335 & 0.375 & 0.412 & 0.281 & 2.506 & -0.342 & 0.461 & 0.336 & 0.522 & 2.128 \\
\hline $\begin{array}{l}10,001- \\
50,000\end{array}$ & -0.013 & 0.002 & -0.001 & -0.001 & -0.000 & -0.050 & 0.057 & 0.009 & -0.020 & -0.001 & -0.293 & 0.337 & -0.037 & -0.348 & -0.307 & -0.289 & 0.082 & -0.005 & -0.409 & -0.389 \\
\hline $\begin{array}{l}50,001- \\
500,000\end{array}$ & 0.019 & -0.001 & 0.000 & -0.001 & -0.000 & 0.089 & -0.068 & -0.020 & 0.008 & -0.006 & 0.650 & -0.736 & -0.288 & 0.609 & -1.458 & 0.099 & -0.332 & -0.238 & 0.245 & -1.205 \\
\hline
\end{tabular}

(a) Reference variable is the household headed by an unschooled person.

(b) Reference variable is the household that lives in the biggest towns, precisely those living in town with more than 500,000 inhabitants. 
Table 9. Shadow prices for all considered nutrients $€$ cents

\begin{tabular}{lccccc|c}
\hline & Beef & Pork & Poultry & Fish & Eggs & MEAN \\
\hline Energy (cal) & -0.018 & -0.001 & -0.001 & -0.009 & 0.000 & -0.006 \\
Proteins (gr) & 2.010 & 0.659 & 0.669 & 0.658 & 0.014 & 0.802 \\
Carbohydrates (gr) & -0.150 & -0.014 & -0.004 & -0.043 & 0.002 & -0.042 \\
Lipids (gr) & 0.220 & 0.025 & -0.011 & 0.043 & 0.001 & 0.056 \\
Vitamin (mg) & -0.034 & 0.000 & 0.002 & 0.011 & 0.001 & -0.004 \\
Fibre (gr) & 2.366 & -0.038 & 0.475 & -0.100 & -0.018 & 0.537 \\
Calcium (mg) & -0.018 & -0.023 & -0.008 & -0.015 & 0.000 & -0.013 \\
O.Minerals (mg) & -0.403 & -0.072 & -0.129 & -0.097 & -0.004 & -0.141 \\
\hline
\end{tabular}

Table 10. Elasticities from an AIDS model without nutrients, calculated at mean values ${ }^{\text {(a) }}$

\begin{tabular}{l|ccccc|ccccc}
\hline & \multicolumn{3}{|c|}{ Elasticity of participation } & \multicolumn{3}{c}{$\begin{array}{c}\text { Elasticity of the unconditional } \\
\text { level of consumption }\end{array}$} \\
\hline & Beef & Pork & $\begin{array}{c}\text { Poul } \\
\text { try }\end{array}$ & Fish & Eggs & Beef & Pork & $\begin{array}{c}\text { Poul } \\
\text { try }\end{array}$ & Fish & Eggs \\
\hline Price of beef & $-0.04^{*}$ & 0.003 & -0.017 & -0.003 & 0.001 & $-0.53^{*}$ & $-0.36^{*}$ & -0.11 & -0.01 & -0.03 \\
Price of pork & $0.05^{*}$ & -0.01 & 0.002 & 0.007 & 0.001 & $0.25^{*}$ & $-0.86^{*}$ & -0.03 & $0.13^{*}$ & 0.01 \\
Price of poultry & -0.02 & 0.002 & -0.006 & -0.004 & $-0.01^{*}$ & $0.19^{*}$ & -0.10 & $-0.88^{*}$ & $0.14^{*}$ & 0.02 \\
Price of fish & $0.06^{*}$ & -0.01 & 0.010 & $-0.01^{*}$ & $0.01^{*}$ & $0.23^{*}$ & $-0.23^{*}$ & $-0.15^{*}$ & $-0.59^{*}$ & $-0.20^{*}$ \\
Price of eggs & -0.02 & $-0.04^{*}$ & 0.018 & $0.04^{*}$ & $-0.01^{*}$ & 0.11 & -0.08 & -0.09 & -0.12 & $-0.66^{*}$ \\
$\begin{array}{l}\text { Price rest of } \\
\text { foods }\end{array}$ & -0.05 & 0.02 & $-0.02^{*}$ & -0.003 & $-0.01^{*}$ & $-0.54^{*}$ & $-0.50^{*}$ & -0.05 & $-0.18^{*}$ & $-0.36^{*}$ \\
Expenditive & $0.12^{*}$ & $0.07^{*}$ & $0.04^{*}$ & $0.03^{*}$ & $0.01^{*}$ & $1.58^{*}$ & $1.29^{*}$ & $0.86^{*}$ & $1.21^{*}$ & $0.79^{*}$ \\
\hline
\end{tabular}

* significant at the 5\% level. 
Table 11. Significance differences testing between elasticities of models with and without nutrients

\begin{tabular}{|c|c|c|c|c|c|c|c|c|c|c|}
\hline & \multicolumn{5}{|c|}{ Elasticity of participation } & \multicolumn{5}{|c|}{$\begin{array}{c}\text { Elasticity of the unconditional } \\
\text { level of consumption }\end{array}$} \\
\hline & Beef & Pork & $\begin{array}{c}\text { Poul } \\
\text { try }\end{array}$ & Fish & Eggs & Beef & Pork & $\begin{array}{c}\text { Poul } \\
\text { try }\end{array}$ & Fish & Eggs \\
\hline Pric of beef & $9.30^{*}$ & 1.61 & $16.6^{*}$ & $5.0^{*}$ & $18.0^{*}$ & 1.49 & $2.55^{*}$ & $16.7^{*}$ & $17.6^{*}$ & $3.37 *$ \\
\hline Price of pork & $2.96^{*}$ & $5.87^{*}$ & $18.9^{*}$ & $8.8^{*}$ & $2.11^{*}$ & $20.7^{*}$ & $8.44^{*}$ & $97.2^{*}$ & $14.0^{*}$ & $99.2^{*}$ \\
\hline Price of poultry & $27.5^{*}$ & $10.6^{*}$ & $3.82 *$ & $15.5^{*}$ & $11.3^{*}$ & $10.9^{*}$ & $67.1^{*}$ & $36.7 *$ & $5.22 *$ & $86.9^{*}$ \\
\hline Price of fish & 0.85 & $16.5^{*}$ & $13.0^{*}$ & $2.2^{*}$ & $16.9^{*}$ & $18.0^{*}$ & $15.0^{*}$ & $15.2^{*}$ & $1.86^{*}$ & $11.2^{*}$ \\
\hline Price of eggs & $31.0^{*}$ & $7.11^{*}$ & $19.6^{*}$ & $21.4^{*}$ & $11.7^{*}$ & $43.6^{*}$ & $29.8^{*}$ & $27.5^{*}$ & $50.8^{*}$ & $34.9^{*}$ \\
\hline $\begin{array}{l}\text { Price rest of } \\
\text { foods }\end{array}$ & $30.9^{*}$ & $12.4^{*}$ & $16.1^{*}$ & $12.3^{*}$ & $2.8^{*}$ & $50.9^{*}$ & $9.8^{*}$ & $13.7^{*}$ & $13.7^{*}$ & $22.8^{*}$ \\
\hline Expenditive & $18.1^{*}$ & $10.6^{*}$ & $4.9^{*}$ & $7.2^{*}$ & $4.72 *$ & $7.44^{*}$ & $53.8^{*}$ & $17.6^{*}$ & 1.89 & $9.76^{*}$ \\
\hline
\end{tabular}

* significant at the 5\% level. 


\section{NOTES}

${ }^{1}$ The FAO suggests that the protein contribution to total energy intake should lie between 12 and $15 \%$.

${ }^{2}$ Food expenditure at home represents $91.2 \%$ of total food expenditure. Fish and eggs expenditure shares are included in the same system because they are assumed to be close substitutes for meat when preparing meals, since they are also an important source of protein in Spain.

${ }^{3}$ Furthermore, with respect to meats, the model proposed by Gao at al. (1997a) captures the essence of the present model.

${ }^{4}$ The assumptions considered up until now summarize consumer's preferences in terms of a utility function whose contours (indifference curves) are strictly convex towards the origin.

${ }^{5}$ These two latest assumptions, together with the previous ones, guarantee that the consumer's preferences can be expressed in terms of an ordinal utility function of the neoclassical type.

${ }^{6}$ Capital stocks are considered fixed in the short-run.

${ }^{7}$ See the discussion on this topic in Gao at al. (1997a).

${ }^{8}$ We say "in general" because there are some specific segments of population for which this may not be absolutely true, for instance those engaging in sports.

${ }^{9}$ As prices are recorded, unit values are taken as proxies for market prices after adjusting them by quality effects. This adjustment results from the estimation of a hedonic equation that relates unit values to product qualities. Cowling and Raynor (1970), Cox and Wohlgenant (1986), Gao et al. (1995) and Gao et al. (1997b) use similar price adjustments.

${ }^{10}$ Since total nutrient intakes are calculated by applying conversion factors to the consumed quantities, it could be a problem of econometric endogeneity.

${ }^{11}$ In Spain, obesity is not as worrisome problem as in other countries (the United States, for instance) while, perhaps, the opposite disease, anorexia, is becoming a more important problem.

${ }^{12}$ Shares of zero responses are: beef, $20.9 \%$; pork, $22.6 \%$; poultry, $10.8 \%$; fish, $8.1 \%$; and eggs, $10.9 \%$.

${ }^{13}$ Due to the heterogeneity of the 'other food' category, results for this group are not presented in this paper.

${ }^{14}$ Heteroscedasticity tests are calculated under the hypotheses that total per capita food expenditure, energy intake, lipids intake and proteins intakes are the main source of the heteroscedastic problem.

${ }^{15}$ In the case of beef, zero responses could also be explained by subjective factors (appearance, taste...).

${ }^{16}$ Mathematical expressions of these elasticities are presented in the Appendix.

${ }^{17} \mathrm{We}$ thank to an anonymous referee for this suggestion. 